38 Sainsbury Centre for Mental Health. In the Dark. The Mental Health Implications of Imprisonment for Public Protection. Sainsbury Centre for Mental Health, 2008.

39 Ministry of Justice. Prison Population Projections 2009-2015: England and Wales. Ministry of Justice, 2009

40 Clark T. Sentencing dangerous offenders following the Criminal Justice and Immigration Act 2008, and the place of psychiatric evidence. J Forensic Psychiatr Psychol 2011; 22: 138-55.

41 Mullen PE. Forensic mental health. Br J Psychiatry 2000; 176: 307-11.
42 Royal College of Psychiatrists. The psychiatrist, courts and sentencing: the impact of extended sentencing on the ethical framework of forensic psychiatry. Council Report CR129, June 2004. Psychiatr Bull 2005; 29 : 73-7.

43 Royal College of Psychiatrists. Court Work (College Report CR147). Royal College of Psychiatrists, 2008.

44 American Psychiatric Association. The Principles of Medical Ethics with Annotations Especially Applicable to Psychiatry. 2009 Edition Revised. APA, 2009.

45 General Medical Council. Good Medical Practice. GMC, 2009.

\title{
Transitional object
}

\section{Jeremy Holmes}

The majority of young children have a favoured 'object' to which they turn when stressed or sleepy. The psychoanalyst Winnicott's genius was to theorise this everyday phenomenon. The transitional object is 'transitional' in that it bridges the borderland between 'me' and 'not-me', safely containing children's desires and projections. With its nostalgic maternal resonance, the transitional object comforts and distracts when the parent is absent, helping the child to forge an independent sense of self. For Winnicott transitional objects are the prototype for culture and creative living. Psychotherapy is 'learning to play': re-establishing transitional space in a traumatising and unresponsive world. 